\title{
Primado petrino: posições, exercício, perspectivas
}

\author{
Petrine primacy: positions, \\ exercise, perspectives
}

Renato da Silveira Borges Neto

\section{Resumo}

O artigo procura analisar a questão do Primado petrino colocando em evidência a necessidade de se encontrar uma base neotestamentária comum para a sua discussão, bem como os últimos passos dos diálogos bilaterais entre a Igreja Católica e as Igrejas Ortodoxas, Anglicanas e Luteranas. A esse respeito busca-se perceber o movimento de aprofundamento do diálogo que, às vezes, revela avanços e outras vezes, velhas dificuldades. Ressalta-se o papel do Papa João Paulo II como fomentador do diálogo em torno do exercício do ministério petrino do Papa, através de seu convite a todos os pastores e teólogos - tanto católicos quanto de outras Igrejas - para que encontrem uma nova forma de exercício do Primado com uma compreensão que possa ser compartilhada por todos. Por fim, dá-se espaço à renúncia do Papa Bento XVI - lido em termos positivos pelo movimento ecumênico - e à eleição do Papa Francisco, o qual enfatizou, já desde sua primeira aparição como Papa, ser o "Bispo de Roma", título portador de grande valor ecumênico para as Igrejas.

Palavras-chave: Primado petrino; Ecumenismo. 


\begin{abstract}
The article analyzes the issue of Petrine Primacy putting in evidence the need to find a common basis of New Testament for its discussion, as well as the last steps of the bilateral dialogues between the Catholic Church and the Orthodox, Anglican and Lutheran churches. In this regard we seek to realize the movement to strengthen dialogue that sometimes reveals advances and sometimes old difficulties. We emphasize the role of Pope John Paul II as a promoter of dialogue on the exercise of Petrine ministry of Pope, through his invitation to all pastors and theologians - catholics and from other churches to find that new forms of exercising the primacy that are shared by all. Finally, there is space for the resignation of Pope Benedict XVI - read in positive terms by the ecumenical movement - and the election of Pope Francis that, since the first public appearance as Pope, calls himself Bishop of Rome, ecumenical title of great value between churches.
\end{abstract}

Keywords: Petrine primacy; Ecumenism.

\title{
Introdução
}

"Por "primado petrino" se entende o primado do sucessor de Pedro, isto é, o peculiar ministério do bispo de Roma a serviço da Igreja universal, da Igreja de Cristo, da Igreja una e única, santa, católica e apostólica. Às vezes, ele é chamado "ministério petrino" (do Papa)"

Ao redor deste peculiar ministério de unidade de toda a Igreja de Cristo gira uma série de problemáticas que hoje - mais do que antes - são fundamentais para que estas mesmas Igrejas possam dar um testemunho unívoco, concreto e crível ao mundo contemporâneo, invadido por uma acelerada secularização. Dever-se-ia, portanto, partir de uma base comum - neotestamentária - que pudesse ser compartilhada por todas as Igrejas, passando a uma acurada análise do primeiro milênio da Igreja, período em que esta não se encontrava formalmente dividida, em busca das formas que tiveram um papel de verdade para a Igreja indivisa. É o que se está fazendo nos últimos anos.

A Igreja católica tem hoje - talvez, também, mais do que antes - uma percepção bastante clara, dupla consciência: primeiro a de que conservou, $n a$

\footnotetext{
${ }^{1}$ Valentini, D. "Primato romano". In: Calabrese, G. - Goyret, P. - Piazza, O. Dizionario di Ecclesiologia. Roma: Città Nuova, 2010, pp. 1128-1150, p. 1128.
} 
fidelidade à tradição apostólica e à fé dos Padres da Igreja, no ministério do Bispo de Roma, o sinal visivel e o garantidor da unidade de toda a Igreja; depois, de que esse mesmo ministério constitui uma dificuldade para a maior parte dos outros cristãos ${ }^{2}$. Assim, sabe que possui uma responsabilidade muito particular neste processo. Seu desafio é procurar a abertura sem colocar em risco a fidelidade ao divino Mestre e à Tradição viva da Igreja.

\section{O Primado Petrino no Novo Testamento: base comum?}

O papel proeminente do apóstolo Pedro nos escritos do Novo Testamento é só muito dificilmente posto em questão, mesmo pelas igrejas mais críticas àquela católica. De fato, os vestígios do primado petrino são facilmente demonstráveis a partir do NT: se manifestam em praticamente todas as tradições neotestamentárias - nos Sinóticos, nos Atos dos Apóstolos, no corpus paulinus, bem como na tradição joanina ${ }^{3}$.

Citemos somente alguns exemplos de momentos em que o primado petrino se faz notar:

a) É Pedro que é apresentado como o primeiro testemunho da ressurreição (cf. 1Cor 15,3-7), com uma fórmula de fé que é anterior ao próprio Paulo ("Eu vos transmiti primeiramente o que eu mesmo havia recebido", v. 3). Também Lc 24,34 segue a mesma linha.

b) Em diversas ocasiões foi ele o porta-voz do grupo dos doze (entre elas, Jo 6,66-69).

c) Paulo, depois de três anos de pregação, vai até Jerusalém para encontrar Pedro por 15 dias, com quem, particularmente, deve discutir e mensurar a sua pregação (cf. Gl 1,18).

d) Pedro aparece também entre os três apóstolos do grupo privilegiado de Jesus: Pedro, Tiago e João (cf. Mc 9,2ss; 14,33ss; Mt 26,36).

e) É ele quem aparece em primeiro lugar nas listas dos doze apóstolos manifestadas pelos Sinóticos e nos Atos dos Apóstolos: "Primeiro Simão, chamado Pedro" (Mt 10,2; cf. Mc 3,16; cf. Lc 6,14; cf. At 1,13).

${ }^{2}$ Cf. João Paulo II. Discurso ao Conselho Ecumênico de Igrejas (Genebra, 12 jun. 1984). In: Garuti, A. Saggi di ecumenismo. Roma: Pontificium Athenaeum Antonianum, 2003, p. 157.

${ }^{3}$ Cf. Valentini, D. "Papa”. In: Barbaglio, G. - Bof, G. - Dianich, S. Dizionario di Teologia. Milano: San Paolo, 2002, pp. 1064-1086, p. 1067. 
f) O livro dos Atos dos Apóstolos se refere também a Pedro em relação ao grupo dos demais, como chefe e porta-voz do colégio apostólico: "Pedro $[\ldots]$ com os outros onze" (At 2,14; 2,37; 5,29).

g) Há também o texto de Mt 16,17-19 que passou a ser tido - a partir da metade do III século - como o fundamento neotestamentário específico do primado 4 . Antes disso, "Roma ligava a sua responsabilidade sobre toda a Igreja com o fato de que em Roma Pedro e Paulo, no auge da sua pregação e testemunho pelo Mestre, sofreram o martírio, estando presentes com as suas relíquias, autoridade e ensinamento apostólico"s.

h) Em Lc 22,32 é possível encontrar também o que seria a versão lucana do primado petrino: "Confirma os teus irmãos".

i) O Evangelho de João indica o primado ligado à misericórdia de Deus (assim como o texto de Lucas) em Jo 20,23 e 21,15-19.

j) Pedro aparece ainda como o guardião da fé contra o falso ensinamento na interpretação das Escrituras (cf. 2Pt 1,20ss).

Poder-se-ia concluir com a afirmação direta de Donato Valentini: "Sinteticamente: se dá um primado de Pedro". E mais: "Mt 16,16-19, Jo 21 e a 1 e 2Pd mostram a consciência por parte da segunda geração cristã, da função de símbolo de unidade de Pedro em relação às três correntes judeu-cristã, paulina e joanina do cristianismo primitivo" $"$.

\section{O Primado Romano no olhar das Igrejas Ortodoxas, Anglicanas e Luteranas}

A partir da base neotestamentária apresentada, poder-se-ia chegar à conclusão de que o que parece ser indiscutivelmente mais problemático é a questão, não de que exista um primado petrino - o que estaria já bastante óbvio -, mas de que interpretação e alcance dar a ele? Talvez sim, talvez não. O êxito do diálogo ao nível do ministério petrino do Papa em particular é,

\footnotetext{
${ }^{4}$ Cf. Legrand, H. “Papa”. In: Lacoste, J.-Y. (Ed.). Dizionario Critico di Teologia. Roma: Borla/ Città Nuova, 2005, pp. 977-980, p. 979.

${ }^{5}$ Valentini, D. “Papa”, p. 1068.

${ }^{6}$ Ibid., p. 1067.

${ }^{7}$ Valentini, D. “Papa”, p. 1068.
} 
como aquele ecumênico em geral, muito variado, mostrando-se diferente às vezes radicalmente - de igreja a igreja. Em algumas destas interpretações chegou-se a uma avaliação positiva e elementos comuns do primado foram encontrados, mas em outras se chegou mesmo à conclusão de que sequer exista um primado.

\subsection{Diálogo com os Ortodoxos}

No âmbito ortodoxo, já no ano de 1983, o editorial da revista La Civiltà cattolica fazia entender o longo caminho que seria necessário para se chegar à discussão sobre o Primado petrino em vista da plena e visível unidade entre as Igrejas ortodoxas e católica romana. Depois de demarcar os próximos temas de debate - fé e comunhão nos sacramentos; os sacramentos da iniciação, as suas relações e a unidade da Igreja, além do reconhecimento destes sacramentos entre as diversas Igrejas -, o editorial apontava para aqueles problemas posteriores no debate, "mais decisivos para a plena unidade entre a Igreja católica e a Igreja ortodoxa", dentre os quais, "a questão do primado do papa".

O diálogo com os Ortodoxos - que passou a acontecer através da Comissão mista internacional da Igreja ortodoxa e da Igreja católica romana - chegou, em sua $5^{\mathrm{a}}$ sessão plenária, a afirmações importantes, tais como que, tanto no Oriente como no Ocidente foram conhecidas diversas formas no exercício da comunhão entre os bispos: troca de epístolas, visitas e, especialmente, o sínodo e o concílio. Também que foi se distinguindo, desde os primeiros séculos, uma hierarquia (taxis) entre as Igrejas mais antigas e as de mais recente fundação, mães e filhas, de cidades maiores e de cidades mais periféricas, diferença que logo encontrou a sua expressão canônica formulada pelos concílios, especialmente pelos cânones que foram aceitos pelo Oriente e Ocidente, mesmo se, às vezes, com interpretação diferente de cada lado. Assim, chegou-se a formulação do conceito de Pentarquia: Roma, Constantinopla, Alexandria, Antioquia e Jerusalém ${ }^{10}$. Diz ainda o documento que, ao nível sinodal,

\footnotetext{
${ }^{8}$ Editoriale. La Civiltà cattolica. "L'Ecumenismo alla prova. Dal 'Dialogo della carità' al 'Dialogo della verità'”. Quaderno 3182 (15 gennaio 1983), pp. 105-121, p. 111.

${ }^{9}$ Ibid., p. 111.

${ }^{10}$ Cf. Comissione mista internazionale della Chiesa ortodoxa e della Chiesa CattoLICA ROMANA. Il sacramento dell'Ordine nella struttura sacramentale della Chiesa (in particolare la sucessione apostolica per la santificazione e l'unità del popolo di Dio. Valamo (Finlandia), 26 giugno 1988: EOE, III, pp. 1812-1866, p. 1863. Apud: VALENTINI, D. Il primato del vescovo de Roma a 40 anni dal Decreto conciliare 'Unitatis Redintegratio'. In: VAlentini, D. (Ed.). In
} 
dá-se uma ação conjunta dos Bispos sob a presidência daquele que reconhecem como o primus inter pares. De fato, segundo o cânon 34 dos Apóstolos, presente na tradição canônica das nossas Igrejas, o primeiro dos Bispos não decide nada que não esteja de acordo com os outros bispos e estes não decidem nada de importante sem o acordo do primeiro. ${ }^{11}$

De fato, o cânon 34 dos Apóstolos - texto do séc. IV fundamental para a eclesiologia oriental - traduz-se para o Oriente como uma «descrição normativa antiga da estrutura hierárquica interna cristã $\rangle^{12}$.

Um documento mais recente da mesma Comissão, em sua $10^{\mathrm{a}}$ sessão plenária, nos dá ideia do estado da questão na atualidade. O documento $A s$ conseqüências eclesiológicas e canônicas da natureza sacramental da Igreja. Comunhão eclesial, conciliaridade e autoridade ficou mais conhecido como Documento de Ravenna (Ravenna, 13 out. 2007). Foi a primeira vez que se discutiu no âmbito do diálogo católico-ortodoxo sobre a questão da conciliaridade e autoridade ao nível universal. O documento explicita que

Ambas as partes concordam sobre o fato que tal taxis canônica era reconhecida por todos na época da Igreja indivisa. Além do mais, concordam sobre o fato que Roma, enquanto Igreja que "preside na caridade", segundo a expressão de Santo Inácio de Antioquia (Aos Romanos, Prólogo), ocupava o primeiro lugar na taxis, e que o bispo de Roma é, portanto, o protos entre os patriarcas. Todavia, eles não estão de acordo sobre a interpretação dos testemunhos históricos desta época no que se refere às prerrogativas do bispo de Roma enquanto protos, questão compreendida de modo diferente já no primeiro milênio. ${ }^{13}$

cammino verso l'unità dei cristiani. Bilancio ecumênico a 40 anni dall'Unitatis Redintegratio'. Roma: LAS, 2005, pp. 15-73, p. 15.

${ }^{11}$ Comissione mista internazionale della Chiesa ortodoxa e della Chiesa cattoLiCA Romana.: Il sacramento dell'Ordine, p. 1864. Apud: VAlentini, D. Il primato del vescovo de Roma, pp. 18-19.

${ }^{12}$ Kasper, W. (Ed.). Il ministero Petrino: Cattolici e Ortodossi in dialogo. Roma: Città Nuova, 2004, p. 147.

13 Comissione mista internazionale della Chiesa ortodoxa e della Chiesa CATTOLICA ROMANA. Le conseguenze ecclesiologiche e canoniche della natura sacramentale della Chiesa. Comunione ecclesiale, conciliarità e autorità, 41. Disponível em: <http:// www.vatican.va/roman_curia/pontifical_councils/chrstuni/ch_orthodox_docs/rc_pc_ chrstuni_doc_20071013_documento-ravenna_it.html>. Acesso em: 22 abr. 2013. 
O documento menciona também que «A conciliaridade a nível universal, exercitada nos concílios ecumênicos, implica um papel ativo do bispo de Roma, enquanto protos entre os bispos de sedes maiores, no consenso da assembleia dos bispos» ${ }^{14}$. Mas também que:

No que se refere ao primado nos seus diversos níveis, desejamos afirmar os seguintes pontos:

1. O primado, em todos os níveis, é uma prática firmemente fundada na tradição canônica da Igreja.

2. Mesmo que o fato do primado em nível universal seja acentuado pelo Oriente e pelo Ocidente, existem diferenças no compreender seja o modo segundo o qual ele deveria ser exercitado, seja os seus fundamentos escriturísticos e teológicos. ${ }^{15}$

Os avanços estão mais claros, mas também as diferenças. Uma afirmação importante é ainda a que o «Primado e conciliaridade são reciprocamente interdependentes. Por tal motivo, o primado nos diversos níveis da vida da Igreja, local, regional e universal, deve ser sempre considerado no contexto da conciliaridade e, analogamente, a conciliaridade no contexto do primado» ${ }^{16}$. Tal declaração aponta para a estima que a igreja Ortodoxa nutre em relação à igreja a nível local, mas também revela a importância de se estar em comunhão com o primado a nível universal. Deste entendimento nasce, por assim dizer, uma plataforma eclesiológica comum sobre a qual fundar a discussão sobre o primado do Bispo de Roma: o «prôtos - kephalê» a nível local é o Bispo, a nível regional é o Patriarca e a nível universal é o Papa.

No último ponto do documento se reafirma que ele é uma expressão de crescimento do diálogo bilateral ${ }^{17}$ e que alguns aspectos devem ser estudados e aprofundados posteriormente, como o papel do Bispo de Roma na comunhão de todas as Igrejas; a função específica da "primeira sede" numa eclesiologia de koinonia (em vista da relação conciliaridade - primado); e em que modo o ensinamento do Concílio Vaticano I e II pode ser compreendido e vivido à luz da prática eclesial do primeiro milênio ${ }^{18}$. Estas questões são colocadas como

\footnotetext{
${ }^{14}$ Ibid., 42.

${ }^{15}$ Ibid., 43.

${ }^{16}$ Ibid., 43.

${ }^{17}$ Cf. Ibid., 46.

${ }^{18}$ Cf. Ibid., 45.
} 
«interrogações cruciais para o nosso diálogo e para as nossas esperanças de restabelecer a plena comunhão entre nós» ${ }^{19}$.

Segue sendo elemento de estudo e preocupação, especialmente do lado católico, os pontos que devem ser aprofundados no sentido de superar afirmações que esvaziem a própria natureza do primado, como o que vê no primado somente um primo inter pares (se entendido simplesmente como primado de "honra", sem nenhuma autoridade ou potestas de fato, somente moral), que o vê somente como de direito humano, não como de direito divino ${ }^{20}$ ou que não aceita uma sucessão pessoal de Pedro no bispo de Roma.

\subsection{Diálogo com os Anglicanos}

Em relação ao diálogo com os anglicanos, iniciado há mais de 40 anos com o histórico encontro entre o Arcebispo anglicano Michael Ramsay e o Papa Paulo VI, em Roma, desde o início ficou claro que entre as tarefas urgentes e importantes estava aquela da autoridade na Igreja. Tal diálogo realizado através da Comissão Internacional Anglicana-Católica Romana (ARCIC) - está na terceira fase (2011-hoje) e compreendeu diálogos entre os anos 1970-1982 (primeira fase) e 1983-2011 (segunda fase). Desde o início, porém, as questões acerca do primado petrino foram prementes, surgindo expressamente pela primeira vez no documento intitulado The Final Report (ARCIC I, 1981), que compreende importantes documentos sobre o assunto, como Authority in the Church I (1976); Authority in the Church: elucidations

\footnotetext{
${ }^{19}$ Ibid., 45.

${ }^{20}$ Interessante, porém, é a posição de alguns teólogos ortodoxos em relação ao primado - mesmo se as questões não ficam resolvidas -, como a do metropolita de Pérgamo, Jonh Zizioulas: «Para um grupo de teólogos ortodoxos de renome, a existência de primados não é uma questão de direito divino, mas de direito humano, devida a circunstâncias históricas, e é um 'simples primado de honra e de ordem'. Essa última é uma expressão ambígua. De fato, na Igreja ortodoxa não existe um simples primado de honra, mas há também espaço para um certo exercício de jurisdição. [...] Alguns invocam um tipo de conciliarismo, mas a sinodalidade não pode existir sem primado. O Vaticano II abre a estrada introduzindo a Teologia da igreja local. Entretanto, alguns teólogos ortodoxos enfatizaram a Igreja local até o ponto que a autocefalia obscurece a importância da unidade ortodoxa em nível universal. [...]O problema entre ortodoxos e católicos permanece grave, mas os progressos mais prováveis se farão com uma eclesiologia de comunhão; uma Igreja formada de Igrejas locais plenamente unidas em uma única Igreja sem perder a sua plenitude eclesial: o primado é meio necessário para realizar e garantir um tal equilíbrio entre o um e os muitos» (ZIzioulas, J. Recent Discussions on Primacy in Ortodox Theology. In: KASPER, W. [Ed.] Il ministero petrino. Cattolici e ortodossi in dialogo. Roma, 2004, pp. 264-265. Apud: Valentini, D. Il primato del vescovo de Roma, p. 21).
} 
(1981); Authority in the Church II (1981), dois documentos de consenso e um de elucidações a respeito de diferenças sobre autoridade na Igreja.

Uma afirmação importante foi:

Para que a vontade de Deus sobre a unidade de todas as comunidades cristãs no amor e na verdade possa dar-se, o modelo de complementaridade entre os aspectos primaciais e conciliares da episcopé ao serviço da koinonia das igrejas deve ser realizado sob o plano universal. A única sé que reivindica o primado universal, e que exercitou e exercita ainda esta episcopé, é a sede de Roma, cidade em que foram mortos Pedro e Paulo. Parece apropriado que, em qualquer eventual futura união, o primado universal tal qual o descrevemos seja exercitado por esta sede. ${ }^{21}$

E ainda, em May the all be one: «Não temos dificuldade com a visão antiga pela qual a Igreja de Roma e o Bispo de Roma teriam uma responsabilidade particular no exprimir e salvaguardar a unidade da Igreja $\rangle^{22}$.

No ARCIC II - no documento intitulado The gift of authority. Authority in the Church III (1999), nn. 45-49 - com o sub-título Primazia: O exercício da autoridade em Colegialidade e Conciliaridade, se diz expressamente:

Dentro de seu ministério mais amplo, o Bispo de Roma oferece um ministério específico relativo ao discernimento da verdade, como expressão de primazia universal. Esse serviço particular tem sido fonte de dificuldades e mal-entendidos nas igrejas. Toda definição solene pronunciada da cátedra de Pedro na igreja de Pedro e Paulo expressa, entretanto, apenas a fé da Igreja. Qualquer definição dessas é pronunciada dentro do colégio daqueles que exercem a episcope e não fora dele. Esse ensinamento autorizado é um exercício particular do chamado e da responsabilidade do corpo de bispos de ensinar e afirmar a fé. Quando a fé é articulada dessa forma, o Bispo de Roma proclama a fé das igrejas locais. Assim, é todo o ensinamento confiável de toda a Igreja que opera no julgamento do primaz universal. Ao formular solenemente tal ensinamento, o primaz

\footnotetext{
${ }^{21}$ ANGLICAN/ROMAN CATHOLIC INTERNATIONAL COMMISSION. Authority in the Church I (1976), 23. Disponível em: <http://www.vatican.va/roman_curia/pontifical_councils/ chrstuni/angl-comm-docs/rc_pc_chrstuni_doc_197609_authority-church-i_en.html $>$. Acesso em: 22 abr. 2013.

${ }^{22}$ House of Bishop of the Church of England. May the all be one. A Response of House of Bishop of the Church of England to 'Ut unum sint', apud: VALENTINI, D. Il primato del vescovo de Roma, p. 23.
} 
universal deve discernir e declarar, com a assistência e a orientação segura do Espírito Santo, em fidelidade à Escritura e à Tradição, a fé autêntica de toda a Igreja, ou seja, a fé proclamada desde o início. É essa fé, a fé de todos os batizados em comunhão, e somente essa, que cada bispo profere com o corpo de bispos em concílio. É essa fé que o Bispo de Roma, em determinadas circunstâncias, tem o dever de discernir e tornar explícita. [...] A recepção da primazia do Bispo de Roma acarreta o reconhecimento desse ministério específico do primaz universal. Acreditamos que isso é um dom a ser recebido por todas as igrejas. ${ }^{23}$

Dessa forma, se reconhece que o serviço oferecido no ministério do Bispo de Roma é essencial à Igreja, afirmando-se claramente que cabe ao Romano Pontífice discernir e declarar, com a assistência e a orientação segura do Espírito Santo, em fidelidade à Escritura è̀ Tradição, a fé autêntica de toda a Igreja. Com isso se afirma também um Magistério - subentendido como infalível - do Colégio dos Bispos, e que o Papa possui o carisma pessoal de infalibilidade que deve, no entanto, ser exercido no contexto da colegialidade episcopal.

Há alguns teólogos anglicanos, porém, que são muito mais suspeitosos. Alguns se orientam ao puro primus inter pares $^{24}$. Outros, como sintetiza Valentini, afirmam categoricamente: «um certo poder, sim, de jurisdição, não; primado, sim, primado de jurisdição universal, não; autoridade repartida, difusa, sim, excessiva centralização, não; guia, sim, 'sobre' a comunidade, não» ${ }^{25}$.

$\mathrm{Na}$ Terceira fase do diálogo (ARCIC III, com seu primeiro encontro realizado no Mosteiro de Bose, Itália, em 2011), a temática de discussão foi a Igreja como Comunhão, local e universal; discutiu-se também como a Igreja local e universal pode vir a discernir a correta formação ética.

Em novembro de 2009 o diálogo com os anglicanos viveu um momento tenso e descrente com a publicação da Constituição Apostólica 'Anglicanorum Coetibus', de Papa Bento XVI, que permitiu, na prática, que inteiras comunidades anglicanas retornassem à unidade com Igreja católica através de uma nova estrutura canônica, o estabelecimento de Ordinariatos Pessoais (espécie de diocese sem limites geográficos, «erigidos pela Congregação para

\footnotetext{
${ }^{23}$ ANGLICAN/ROMAN CATHOLIC INTERNATIONAL COMMISSION. The gift of authority. Authority in the Church III (1999), 47. Disponível em: <http://www.vatican.va/roman_curia/ pontifical_councils/chrstuni/documents/rc_pc_chrstuni_doc_12051999_gift-of-autority_ po.html>. Acesso em: 22 abr. 2013.

${ }^{24}$ Cf. J. Hind apud: VAlentini, D. Il primato del vescovo de Roma, pp. 23-24.

${ }^{25} \mathrm{Cf}$. H. Chadwick apud: Valentini, D. Il primato del vescovo de Roma, p. 24.
} 
a Doutrina da Fé dentro dos confins territoriais de uma determinada Conferência Episcopal, depois de ter consultado a própria Conferência» ${ }^{26}$ ). A Constituição Apostólica permite ainda que as comunidades mantenham as suas tradições litúrgicas e espirituais, mantendo a sua identidade, mas que ainda assim, estejam sob a autoridade do Papa. Para muitos anglicanos esse foi um movimento imperialista e colonizador da parte de Roma ${ }^{27}$. A Comunhão Anglicana a nível mundial já está há anos dividida entre aquelas Igrejas, como a dos EUA, que permite a ordenação de homens abertamente homossexuais e outras que tem posição mais próxima à Igreja católica. Além do mais, algumas outras Igrejas anglicanas - como a da Inglaterra, desde 1994, por exemplo autorizam a ordenação sacerdotal de mulheres. Em meados de 2010 o Sínodo de York aprovou a ordenação de mulheres ao episcopado, decisão que está se impondo dentro da Comunhão Anglicana contra a vontade de comunidades anglicanas tradicionalistas que começam a passar para a Igreja católica através da 'Anglicanorum Coetibus'. De fato, para a Igreja católica, o sim ao episcopado feminino fere profundamente a tradição apostólica mantida por todas as Igrejas do primeiro milênio, tornando-se um novo obstáculo para a plena reconciliação.

\subsection{Diálogo com os Luteranos}

A respeito do diálogo bilateral católico-luterano chegou-se a afirmar: «O diálogo ecumênico mais interessado no Ministério petrino, não o mais avançado, é provavelmente aquele católico-luterano» ${ }^{28}$. Mas o pensamento luterano sobre o Primado petrino ainda é bastante negativo, mesmo que se tenha plena convicção da sua importância. Como afirma W. Pannenberg,

O Papado é um tema desconfortável para os cristãos e para os teólogos, mesmo quando são favoráveis ao movimento ecumênico do nosso século. Preferir-se-ia um ecumenismo sem Papa. Diversos evangélicos disseram o

\footnotetext{
${ }^{26}$ Bento XVI. Constituição Apostólica Anglicanorum coetibus sobre a instituição de Ordinariatos Pessoais para anglicanos que entram na plena comunhão com a Igreja Católica, I.\$1. Disponível em: <http://www.vatican.va/holy_father/benedict_xvi/apost_constitutions/documents/ hf_ben-xvi_apc_20091104_anglicanorum-coetibus_po.html>. Acesso em: 22 abr. 2013.

${ }^{27}$ Cf. Speciale, A. Il dialogo difficile tra cattolici e anglicani. In: "Vatican Insider". Disponível em: $<$ http://vaticaninsider.lastampa.it/nel-mondo/dettaglio-articolo/articolo/chiesa-vaticano-anglicani-church-vatican-anglican-iglesia-anglicanos-vaticano-3590/>. Acesso em: 24 abr. 2013.

${ }^{28}$ Valentini, D. Il primato del vescovo de Roma, p. 25.
} 
mesmo por ocasião da visita do Papa à Alemanha em junho de 1996. Mas a comunhão eclesial com a Igreja católica Romana, que encontra a sua máxima expressão à mesa do Senhor, é impossível sem um entendimento acerca da pretensão do Bispo de Roma de possuir uma particular autoridade sobre a vida de todo o povo cristão. ${ }^{29}$

Entre o resultado de diálogos oficiais e não-oficiais está o documento Communio Sanctorum. A Igreja como comunhão dos santos (2000) do grupo de trabalho bilateral da Conferência Episcopal Alemã e da Igreja Evangélica Luterana Unida da Alemanha, um dos mais atuantes. Nele chegou-se a declarações como: «As afirmações neotestamentárias sobre Pedro mostram que a Igreja primitiva ligou à figura de Pedro funções de um serviço de ensinamento e de pastoral que se referem ao conjunto de comunidades e que são postas de modo particular ao serviço da unidade entre elas» ${ }^{30}$.

Recentemente foi aventada - através do Card. Kurt Koch, presidente do Pontificio Conselho para a Unidade dos Cristãos, idéia que também foi ecoada por Mons. Gerhard Ludwig Müller, prefeito da Congregação para a Doutrina da Fé - a hipótese de estender aos luteranos a fórmula dos "ordinariatos pessoais" usada para os anglicanos, idéia já firmemente rejeitada pelo Secretário geral da Federação Luterana Mundial, o Rev. Martin Junge, para quem tal hipótese geraria uma piora das relações ecumênicas entre as duas Igrejas e «mandaria um sinal errado às Igrejas luteranas que estão se empenhando em afrontar o aniversário da Reforma em um espírito de compreensão e cooperação mútua» ${ }^{31}$. De fato, as Igrejas provenientes da Reforma se preparam para celebrar o seu $500^{\circ}$ aniversário e já convidaram a Igreja católica para participar das celebrações. $\mathrm{O}$ próprio Papa Francisco já encontrou, em audiência privada no Vaticano, o líder dos luteranos na Alemanha, o teólogo e pastor Nikolaus Schneider, ocasião em que o pastor reiterou o convite ao Papa.

Por fim, pode-se afirmar que a situação, não obstante os avanços, é ainda bastante incipiente, como mostra Adriano Garuti, O.F.M.: aos poucos, vai tomando corpo

\footnotetext{
${ }^{29}$ Pannenberg, W. Riflessioni evangeliche circa il ministero petrino del Vescovo di Roma. Apud: VAlentini, D. Il primato del vescovo de Roma, p. 32.

${ }^{30}$ Grupo de Trabalho Bilateral da Conferência Episcopal Alemã e da Direção da Igreja Evangélica luterana Unida da Alemanha (2000), 165. Apud: Ibid., p. 29.

${ }^{31}$ Speciale, A. Un ordinariato luterano? Brutto segnale. In: "Vatican Insider". Disponível em: $<$ http://vaticaninsider.lastampa.it/nel-mondo/dettaglio-articolo/articolo/luterani-lutherans-luteranos-21547/>. Acesso em: 25 abr. 2013.
} 
um certo reconhecimento da necessidade de uma autoridade superior no governo da Igreja, e se nota um certo acordo em atribuir esta autoridade ao seu tradicional detentor, o Bispo de Roma. Tal reconhecimento é, porém, ligado a condições precisas e propostas concretas de renovação. Encontra-se, por isso, o constante coro que afirma que o primado representa até a data de hoje uma pedra de tropeço precisamente porque apresentado nas formulações do Vaticano I, cujas definições são "theologoumena", válidas quando muito somente para a Igreja católica, a única representada ao Concílio. ${ }^{32}$

\section{O chamado ao diálogo em vista do repensamento do exercício do Primado petrino: João Paulo II e a "Encíclica $U t$ unum sint sobre o empenho ecumênico"}

Desde o início de seu pontificado, Papa João Paulo II teve uma atenção particular pelo Grande Jubileu do ano 2000 e, nele, pela questão ecumênica. Era em vista desse evento que Papa Wojtyla se mobilizava para dar a sua própria contribuição para que os cristãos entrassem no terceiro milênio em plena unidade. Grande parte do reaquecimento do debate em torno do Primado petrino nos últimos anos pode ser creditado ao empenho pessoal do Papa, que se mostrava bastante consciente das dificuldades causadas pelo exercício do Primado e, para algumas igrejas, do próprio Primado em si.

Em 1984, no discurso que fez em Genebra, João Paulo II falou que a «convicção da Igreja católica de ter conservado, na fidelidade à tradição apostólica e à fé dos Padres, no ministério do Bispo de Roma, o sinal visível e o garantidor da unidade, constitui uma dificuldade para a maior parte dos outros

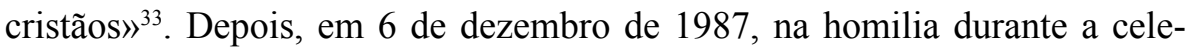
bração da missa em São Pedro na presença do Patriarca ecumênico, sua Santidade Dimitrius I, afirmou:

Sou consciente que, por uma grande variedade de razões e contra a vontade de todos os interessados, aquilo que deveria ser um serviço às vezes se manifestou sob uma luz muito diferente. É na perspectiva desta perfeita comunhão que nós desejamos restabelecer, eu rogo insistentemente ao

\footnotetext{
${ }^{32}$ Garuti, A. Apresentação do volume de U. Betti. A Constituição Dogmática Pastor aeternus do Concílio Vaticano I. apud: Garuti, A. Saggi di ecumenismo, p. 158.

${ }^{33}$ João Paulo II. Discurso ao Conselho Ecumênico de Igrejas (Genebra, 12 jun. 1984). In: GARUTI, A. Saggi di ecumenismo, p. 157.
} 
Espírito Santo para que nos dê a sua luz, e ilumine todos os pastores e teólogos das nossas Igrejas para que possamos procurar, obviamente juntos, as formas nas quais este ministério possa realizar um serviço de amor reconhecido por todos. ${ }^{34}$

Ambas as idéias passaram para um documento oficial da Igreja católica em 1995, a Carta Encíclica Ut unum sint sobre o empenho ecumênico. Mesmo deixando claro que a Igreja católica, dentre todas as Igrejas e Comunidades eclesiais, «está consciente de ter conservado o ministério do Sucessor do apóstolo Pedro, o Bispo de Roma, que Deus constituiu como "perpétuo e visível fundamento da unidade", e que o Espírito ampara para que torne participantes deste bem essencial todos os outros $\rangle^{35}$, o pontífice disse estar igualmente cônscio de que o «ministério do Bispo de Roma, o sinal visível e o garantidor da unidade, constitui uma dificuldade para a maior parte dos outros cristãos, cuja memória está marcada por certas recordações dolorosas $\rangle^{36}$, ou mesmo, o maior obstáculo ${ }^{37}$. Esta carta encíclica - que não traz seus destinatários, como é costume, e por isso se dirige a quem quiser a ela acolher, aos homens e mulheres de boa vontade - é tida como revolucionária pelo então Arcebispo de São Francisco (Califórnia, USA) e Presidente da Conferência Episcopal Americana, Card. John R. Quinn ${ }^{38}$. Afinal, «Pela primeira vez, é o próprio Papa que levanta e torna legítima a questão da reforma e das mudanças na função papal na Igreja. O Papa João Paulo II convida a uma ampla discussão de como essa reforma poderia ser realizada e que perfil deveria tomar» ${ }^{39}$. É o desejo de remover aquele "obstáculo" que faz o Papa chamar todos ao diálogo ${ }^{40}$.

Mesmo se dever-se-ia deixar bastante claro, para evitar ambigüidades, que o diálogo proposto por Papa Woytila é muito mais a nível do exercício do primado - e não da função ou do papado em geral -, é fato que a Carta Encí-

\footnotetext{
${ }^{34}$ João Paulo II. Apud: Garuti, A. Saggi di ecumenismo, p. 157.

${ }^{35}$ Jỗo PaUlo II. Ut unum sint, 88.

${ }^{36}$ Ibid., 88.

${ }^{37}$ Cf. Paulo VI. Discurso aos membros da Secretaria para a Unidade (28 abr. 1967). Insegnamenti di Paolo VI. Vol. VI, Città Del Vaticano, 1968, pp. 192-193, apud: VAlentini, D. Il primato del vescovo de Roma, p. 15.

${ }^{38}$ QuINn, J. Reforma do papado. Indispensável para a unidade cristã. Aparecida/SP: Santuário, 2002, p. 10.

${ }^{39}$ Ibid., p. 10

${ }^{40}$ Cf. Ibid., p. 9.
} 
clica trouxe para muitos uma grande esperança, mesmo se para alguns não tenha acrescentado muito. De fato, o convite é bastante específico: deve-se «encontrar uma forma de exercício do primado que, sem renunciar de modo algum ao que é essencial da sua missão, se abra a uma situação nova» ${ }^{41}$, o que aponta para a existência de elementos essenciais do primado a que não seria lícito renunciar por uma questão de fidelidade ao Evangelho e à Tradição.

Foi no contexto do convite do Santo Padre João Paulo II que, em 1996, a Congregação para a Doutrina da Fé resolveu aprofundar a temática do primado petrino convocando um simpósio internacional - de natureza eminentemente doutrinal - intitulado O Primado do Sucessor de Pedro, que realizou-se no Vaticano. O próprio documento afirma sua finalidade: «Estas 'Considerações' - à margem do Simpósio - querem somente recordar os pontos essenciais da doutrina católica sobre o Primado, grande dom de Cristo à sua Igreja enquanto serviço necessário à unidade» ${ }^{42}$. Dessa forma, desejou-se manifestar «a consciência do quanto não seja factível propor a busca de uma nova forma de exercício concreto do Primado, se não se possui com clareza a doutrina sobre aquilo que é essencial e invariável da própria realidade do Primado» ${ }^{43}$.

O documento da CDF, depois de citar as palavras «Primeiro Simão, chamado Pedro» (Mt 10,2), afirma alguns princípios doutrinais sobre a origem, finalidade e natureza do Primado:

Este elenco, dotado de grande força testemunhal, e outros passos evangélicos mostram com clareza e simplicidade que o cânon neotestamentário recebeu as palavras de Cristo relativas a Pedro e ao seu papel no grupo dos Doze. Por isso, já nas primeiras comunidades cristãs, como mais tarde em toda a Igreja, a imagem de Pedro ficou fixada como aquela do Apóstolo que, não obstante a sua fraqueza humana, foi constituído expressamente por Cristo no primeiro lugar entre os Doze e chamado a desenvolver na Igreja uma própria e específica função. [...] A Igreja, desde os primórdios e com crescente clareza, entendeu que como existe a sucessão dos Apóstolos no ministério dos Bispos, assim também o ministério da unidade, confiado a Pedro, pertence à perene estrutura da Igreja de Cristo, e que esta sucessão é fixada na sede do seu martírio. ${ }^{44}$

\footnotetext{
${ }^{41}$ JoÃo PaUlo II. Ut unum sint, 95.

${ }^{42}$ Congregazione Per la Dottrina della Fede. Il primato del sucessore di Pietro nel mistero della Chiesa, 2. Disponível em: <http://www.vatican.va/roman_curia/congregations/cfaith/documents/ rc_con_cfaith_doc_19981031_primato-successore-pietro_it.html>. Acesso em: 22 abr. 2013.

${ }^{43}$ Garuti, A. Saggi di ecumenismo, p. 161.

${ }^{44}$ Congregazione Per la Dottrina della Fede. Il primato del sucessore di Pietro nel mistero della Chiesa, 3.
} 
Depois de reafirmar o conteúdo central da Constituição Pastor aeternus, do Concilio Vaticano I, o documento da CDF afirma:

Por isso, "quando a Igreja Católica afirma que a função do Bispo de Roma responde à vontade de Cristo, essa não separa esta função da missão confiada ao conjunto dos Bispos, também eles 'vigários e legados de Cristo"' (LG, 27). O Bispo de Roma pertence ao seu colégio e aqueles são os seus irmãos no ministério. Se deve também afirmar, reciprocamente, que a colegialidade episcopal não se contrapõe ao pessoal exercício do Primado nem o deve relativizar. [...] O Episcopado e o Primado, reciprocamente conexos e inseparáveis, são de instituição divina. ${ }^{45}$

O documento afirma ainda, sobre características do exercício deste Primado, que este «não é um ofício de coordenação ou de presidência, não se reduz a um Primado de honra, nem pode ser concebido como uma monarquia política $\rangle^{46}$. Partindo de duas premissas fundamentais (a unidade do Episcopado e o caráter episcopal do próprio Primado), se afirma a faculdade de servir à unidade de todos os Bispos e fiéis, bem como a devida obediência ao Bispo de Roma que é o garante da legitima diversidade de ritos, disciplinas e estruturas eclesiais entre Oriente e Ocidente ${ }^{47}$.

Depois de recordar que o Romano Pontífice é, como todos os outros fiéis, submisso à Palavra de Deus, que tem a faculdade de cumprir atos de governo eclesiástico necessários ou convenientes para promover e defender a unidade de fé e de comunhão e de dar diversos exemplos desse exercício («dar o mandato para a ordenação de novos Bispos, exigir deles a profissão de fé católica; ajudar a todos a manterem-se na fé professada, emanar leis para toda a Igreja, estabelecer estruturas pastorais a serviço de diversas Igrejas particulares, dotar de força vinculante as decisões dos Concílios particulares, aprovar institutos religiosos supra-diocesanos etc»), afirma-se:

Pelo caráter supremo do poder do Primado, não existe nenhuma instância a quem o Romano Pontífice deva juridicamente responder pelo exercício do dom recebido: "prima sedes a nemine iudicatur". Todavia, isso não significa que o papa tenha um poder absoluto. Escutar as vozes das Igrejas é, de fato, uma marca do ministério da unidade, também uma conseqüência

\footnotetext{
${ }^{45}$ Ibid., 5-6.

${ }^{46}$ Ibid., 7.

${ }^{47}$ Cf. Ibid., 8.
} 
da unidade do Corpo episcopal e do sensus fidei do inteiro povo de Deus. ${ }^{48}$

\section{Os recentes passos da Igreja Católica: novas perspectivas?}

Não é possível julgar com precisão (só com o tempo e, retrospectivamente, o será), mas parece possível que algo esteja se movendo em relação ao exercício do Primado nos últimos meses. A renúncia de Papa Bento XVI ao ministério petrino - mesmo se previsto pelo $\mathrm{CIC}^{49}$ - teve enorme repercussão no meio das Igrejas e foi recebido como um grande gesto de humildade, prova de que o Papa também deve responder aos limites que a idade lhe impõe, como de resto, ele mesmo havia afirmado: «Quando um Papa chega à clara consciência de já não se encontrar em condições físicas, mentais e espirituais de exercer o encargo que lhe foi confiado, então tem o direito - e, em algumas circunstâncias, também o dever - de pedir demissão $\rangle^{50}$. Tal gesto fora visto também por alguns como um "fragmento de demitologização"

Em relação à figura do novo Pontífice, Papa Francisco, em pouco tempo já são diversas as atitudes que fazem entender o que alguns estão chamando de auto-reforma ${ }^{52}$. Não é para menos. As palavras de Papa Francisco diante da multidão em sua primeira aparição são muito expressivas:

Irmãos e irmãs, boa noite. Vocês sabem que o dever de um conclave é dar um bispo a Roma. Parece que os meus irmãos cardeais foram buscar-me quase até ao fim do mundo. Mas aqui estamos. Agradeço a vossa hospitalidade. $A$ comunidade diocesana de Roma já tem o seu bispo. Obrigado.

[...] E agora, vamos começar esta jornada: o bispo e o povo. É o caminho da Igreja de Roma, que preside à caridade em todas as igrejas. Um caminho de fraternidade, amor e confiança entre nós.

\footnotetext{
${ }^{48}$ Ibid., 10.

${ }^{49}$ Cf. CIC 331-335.

${ }^{50}$ Bento XVI. Luz do mundo. O papa, a Igreja e os sinais dos tempos. Uma conversa com Peter Seewald. São Paulo: Paulinas, 2011, pp. 48-49.

${ }^{51}$ Cf. RösER, J. Il servitore di Pietro. L'annuncio del ritiro di Benedetto XVI cambia anche la prospettiva del papato e rende ipotizzabili nuovi sviluppi. Disponível em: <http://www.queriniana.it/ blog/il-servitore-di-pietro/246>. Acesso em: 24 abr. 2013.

52 Cf. Tonnielli, A. Francesco e l'auto-riforma della Chiesa. In: "Vatican Insider". Disponível em: <http://vaticaninsider.lastampa.it/vaticano/dettaglio-articolo/articolo/francesco-francis-francisco-23372/>. Acesso em: 25 abr. 2013.
} 
[...] Espero que este caminho da Igreja - que hoje começa e em que serei ajudado pelo cardeal vigário, aqui ao meu lado - seja frutífero para a evangelização desta cidade tão bonita.

[...] Agora, vou abençoar-vos e a todo o mundo, a todos os homens e mulheres de boa vontade. Agora deixo-vos. Obrigado por tamanha hospitalidade. Ver-nos-emos em breve. Amanhã vou rezar à Nossa Senhora para que proteja Roma. Boa noite e bom descanso. (Itálico nosso).

O Papa chama a si mesmo não de pontífice ou papa, mas bispo de Roma; volta-se diversas vezes ao "seu" povo, a comunidade diocesana de Roma; apresenta o seu auxiliar na nova missão, o cardeal vigário da diocese de Roma; Fala da Igreja de Roma que preside na caridade às demais; por fim, abençoa a todos os homens e mulheres de boa vontade, assegurando a sua oração à Maria para que proteja a cidade de Roma. Sinais que rapidamente contaram a favor do Papa no mundo inteiro em geral, e nas Igrejas Orientais em particular.

Outros sinais se seguiram. A escolha do prédio anexo ao Palácio Apostólico, a Residência Santa Marta, como sua morada, a fim de se beneficiar do contato e do diálogo com diversas pessoas que ali se hospedam; a opção por seu anel somente em prata, não em ouro como de costume; a cruz peitoral - de ferro - que continua a mesma de sua ordenação episcopal.

Em uma entrevista, depois de três dias de pontificado de Papa Francisco, o teólogo Enzo Bianchi, fundador e atual prior da Comunidade de Bose, afirmara:

como um adágio recorrente, se define e continua a dizer-se "bispo de Roma", título não só teologicamente essencial, mas também ecumênico: o bispo de Roma é um bispo, vigário de Cristo como o são todos os outros bispos, não um super-bispo, e é Papa da igreja católica enquanto bispo da igreja de Roma que preside na caridade. E quando afirma esta sua qualidade, papa Francisco se apressa em decentralizar-se em relação a "Cristo que é o centro, a referência fundamental, o coração da Igreja, sem o qual Pedro e a Igreja não existiriam". ${ }^{53}$

\footnotetext{
${ }^{53}$ Bianchi, E. Il Pontefice che si è fatto uomo. In: "Vatican Insider". Disponível em: <http:// vaticaninsider.lastampa.it/documenti/dettaglio-articolo/articolo/francesco-francis-francisco-23317/>. Acesso em: 25 abr. 2013.
} 
Ainda dois elementos significativos destes primeiros dias de pontificado. O primeiro: depois de um mês de sua eleição, quase dando uma resposta aos cardeais que antes do conclave pediam uma maior colegialidade no governo da Igreja universal, Papa Francisco anunciou a criação de um "grupo de trabalho" de oito cardeais proveniente dos cinco continentes do mundo para aconselhá-lo no governo da Igreja universal e estudar um projeto de revisão da Constituição Apostólica Pastor bônus, que regula a Cúria Romana desde os tempos de Papa João Paulo II.

O segundo elemento significativo é o desejo de Papa Bergoglio de fazer com que a CEI - Conferência Episcopal Italiana - possa eleger seu Presidente e seu Secretário, visto que ela é a única no mundo a não fazê-lo; a prerrogativa ainda é do Papa, Primaz da Itália e Bispo de Roma.

Todos estes gestos, com todos os outros não citados aqui, fazem esperar por novidades que só o Espírito Santo pode fazer acontecer em sua Igreja.

\section{Conclusão}

“Cum Petrus et sub Petrus". A questão do Primado petrino - seu exercício por parte do Bispo de Roma, sua concordância por parte das outras Igrejas e sua melhor articulação neste específico tempo da Igreja - são ainda um grande desafio. As marcas do passado, empedernidas por testemunhos não tão evangélicos de todas as partes, fizeram com que o desejo de dialogar diminuísse e o fechamento fosse algo quase inevitável. Algo, no entanto, está se movendo tanto do ponto de vista das demais Igrejas, que começam a dialogar sobre o Primado petrino com base objetiva, sem exageros do passado, pautada em estudos bíblicos, arqueológicos e históricos, como da parte da Igreja católica, que começa a voltar-se aos primórdios desejando deixar para trás manifestações daquilo que deveria ser um serviço, mas que às vezes se manifestou sob uma luz muito diferente.

A estrada parece ainda muito longa; os diálogos avançam mais em terrenos bilaterais. Mas as esperanças passaram a ser mais sentidas nos últimos dias, depois da eleição de Papa Francisco. Não que os predecessores não tenham dado contribuições importantes - algumas importantíssimas para que essa divisão fosse superada, pelo contrário. É o momento novo que contagia a todos de esperança, dentro e fora da Igreja. Deseja-se uma Igreja mais pobre e para os pobres. E o momento parece ser propício. Como disse o pregador da Casa Pontifícia, Pe. Raniero Cantalamessa, na sua homilia na 
sexta-feira santa, diante do Santo Padre, dos cardeais e fiéis presentes à Basílica de São Pedro, depois de ter recordado um conto de Franz Kafka ("Uma mensagem imperial"):

Temos de fazer todo o possível para que a Igreja nunca se pareça ao castelo complicado e assombroso descrito por Kafka, e para que a mensagem possa sair dela tão livre e alegre como quando começou a sua corrida. Sabemos quais são os impedimentos que podem reter o mensageiro: as muralhas divisórias, começando por aquelas que separam as várias igrejas cristãs umas das outras; a burocracia excessiva; os resíduos de cerimoniais, leis e disputas do passado, que se tornaram, enfim, apenas detritos. Acontece como em certas construções antigas. Ao longo dos séculos, para adaptar-se às exigências do momento, houve profusão de divisórias, escadarias, salas e câmaras. Chega um momento em que se percebe que todas essas adaptações já não respondem às necessidades atuais; servem, antes, de obstáculo, e temos então de ter a coragem de derrubá-las e trazer o prédio de volta à simplicidade e à linearidade das suas origens. Foi a missão que recebeu, um dia, um homem que orava diante do crucifixo de São Damião: "Vai, Francisco, e reforma a minha Igreja". ${ }^{4}$

Reformar a Igreja deixando intocados os seus fundamentos. Essa é a grande tarefa e o grande desafio do nosso tempo. E no meio do caminho, há Pedro, sinal da unidade. Tal grande tarefa não se fará sem ele.

\section{Referências Bibliográficas}

Bento XVI. Luz do mundo. O papa, a Igreja e os sinais dos tempos. Uma conversa com Peter Seewald. São Paulo: Paulinas, 2011;

. Constituição Apostólica Anglicanorum coetibus sobre a instituição de Ordinariatos Pessoais para anglicanos que entram na plena comunhão com a Igreja Católica (2009). Disponível em: <http://www.vatican.va/ holy_father/benedict_xvi/apost_constitutions/documents/hf_ben-xvi_ apc_20091104_anglicanorum-coetibus_po.html>. Acesso em: 22 abr. 2013;

\footnotetext{
${ }^{54}$ Cantalamessa, R. Homilia na Celebração da Paixão do Senhor (Sexta-feira Santa, 29 mar. 2013). Disponível em: <http://www.vatican.va/liturgical_year/holy-week/2013/documents/ holy-week_homily-fr-cantalamessa_20130329_po.html>. Acesso em: 25 abr. 2013.
} 
Bianchi, E. Il Pontefice che si è fatto uomo. In: "Vatican Insider". Disponível em: <http://vaticaninsider.lastampa.it/documenti/dettaglio-articolo/ articolo/francesco-francis-francisco-23317/>. Acesso em: 25 abr. 2013;

Cantalamessa, R. Homilia na Celebração da Paixão do Senhor (Sextafeira Santa, 29 mar. 2013). Disponível em: <http://www.vatican.va/ liturgical_year/holy-week/2013/documents/holy-week_homily-frcantalamessa_20130329_po.html >. Acesso em: 25 abr. 2013.

Congregazione Per la Dottrina della Fede. Il primato del sucessore di Pietro nel mistero della Chiesa. Disponível em: <http://www.vatican.va/roman curia/congregations/cfaith/documents/rc_con_cfaith_doc_19981031_ primato-successore-pietro_it.html>. Acesso em: 22 abr. 2013;

Editoriale. La Civiltà cattolica. "L'Ecumenismo alla prova. Dal 'Dialogo della carità' al 'Dialogo della verità'”. Quaderno 3182 (15 gennaio 1983);

Garuti, A. Saggi di ecumenismo. Roma: Pontificium Athenaeum Antonianum, 2003;

João Paulo II. Encíclica Ut unum sint sobre o empenho ecumênico (1995). Disponível em: <http://www.vatican.va/holy_father/john_paul_ii/ encyclicals/documents/hf_jp-ii_enc_25051995_ut-unum-sint_po.html $>$. Acesso em: 24 abr. 2013;

Kasper, W. (Ed.). Il ministero Petrino: Cattolici e Ortodossi in dialogo. Roma: Città Nuova, 2004;

Legrand, H. "Papa”. In: Lacoste, J.-Y. (Ed.). Dizionario Critico di Teologia. Roma: Borla/Città Nuova, 2005;

QuinN, J. Reforma do papado. Indispensável para a unidade cristã. Aparecida/ SP: Santuário, 2002;

RöSER, J. Il servitore di Pietro. L'annuncio del ritiro di Benedetto XVI cambia anche la prospettiva del papato e rende ipotizzabili nuovi sviluppi. Disponível em: <http://www.queriniana.it/blog/il-servitore-dipietro/246>. Acesso em: 24 abr. 2013;

Speciale, A. Il dialogo difficile tra cattolici e anglicani. In: "Vatican Insider". Disponível em: <http://vaticaninsider.lastampa.it/nel-mondo/dettaglioarticolo/articolo/chiesa-vaticano-anglicani-church-vatican-anglicaniglesia-anglicanos-vaticano-3590/>. Acesso em: 24 abr. 2013; 
. Un ordinariato luterano? Brutto segnale. In: "Vatican Insider". Disponível em: $<$ http://vaticaninsider.lastampa.it/nel-mondo/dettaglioarticolo/articolo/luterani-lutherans-luteranos-21547/>. Acesso em: 25 abr. 2013;

ToRnielli, A. Francesco e l'auto-riforma della Chiesa. In: "Vatican Insider". Disponível em: $<\mathrm{http}: / /$ vaticaninsider.lastampa.it/vaticano/dettaglioarticolo/articolo/francesco-francis-francisco-23372/>. Acesso em: 25 abr. 2013;

Valentini, D. "Primato romano". In: Calabrese, G. - Goyret, P. - Piazza, O. Dizionario di Ecclesiologia. Roma: Città Nuova, 2010; . Il primato del vescovo de Roma a 40 anni dal Decreto conciliare 'Unitatis Redintegratio'. In: VAlentinI, D. (Ed.). In cammino verso l'unità dei cristiani. Bilancio ecumênico a 40 anni dall' 'Unitatis Redintegratio'. Roma: LAS, 2005; . "Papa". In: Barbaglio, G. - Bof, G. - Dianich, S. Dizionario di Teologia. Milano: San Paolo, 2002.

\section{Renato da Silveira Borges Neto}

Doutor em Teologia Dogmática Pontificia Università di San Tommaso d'Aquino (Angelicum) - Roma Docente no Instituto Superior de Teologia da Arquidiocese do Rio de Janeiro (ISTARJ) e no Instituto Filosófico e Teológico do Seminário Arquidiocesano de Niterói (IFTSJ)

Brasil

E-mail: renatosbn@yahoo.com.br

Recebido em 30/04/13

Aprovado em 08/10/13 